Received: 17 October 2013

Accepted: 21 October 2013

Published online: 12 November 2013

(C) The Author(s) 2013. This article is published with open access at Springerlink.com

Electronic supplementary material The online version of this article (doi:10.1007/s00134-013-3142-2) contains supplementary material, which is available to authorized users.

\section{J. Lanspa}

Division of Pulmonary and Critical Care Medicine, University of Utah School of Medicine, Salt Lake City, UT, USA

\section{S. A. Johnson}

Division of General Internal Medicine, University of Utah School of Medicine, Salt Lake City, UT, USA

e-mail: stacy.a.johnson@hsc.utah.edu

\section{J. Lanspa (}

Intermountain Medical Center, Shock-Trauma Intensive Care Unit, 5121 S. Cottonwood Street, Murray, UT 84107, USA

e-mail: michael.lanspa@imail.org

Tel.: +1-801-5076556

Fax: +1-801-5074699
A 52-year-old man with diffuse large B cell lymphoma was admitted to the intensive care unit with septic shock. He had been chronically ill with limited recovery following internal fixation for a pathologic left tibial fracture and had been residing in a long-term acute care hospital. A peripherally inserted central catheter was placed in the right upper extremity 1 month prior. The catheter was removed upon admission. While imaging the patient's veins for vascular access, gas emboli were noted in the left internal jugular vein. These emboli are recognized as hyperechoic bubbles in the superior aspect of the vessel, with reverberation artifact extending deeper than the vessel (Fig. 1; Supplementary material 1). These emboli were present in the superior portion of the vein, extending above the angle of the jaw. At the time of imaging, the patient had been placed in the reverse Trendelenburg position, with slight right-side dependency. The right internal jugular vein had no evidence of air embolism. The patient experienced no adverse effects from the air embolism. It is suspected that these emboli inadvertently occurred through routine access of his catheter with
Fig. 1 Gas emboli in the left internal jugular vein imaged as hyperechoic bubbles (black arrows) in the superior aspect of the vessel (dashed line), with reverberation artifact extending deeper than the vessel (white arrows)

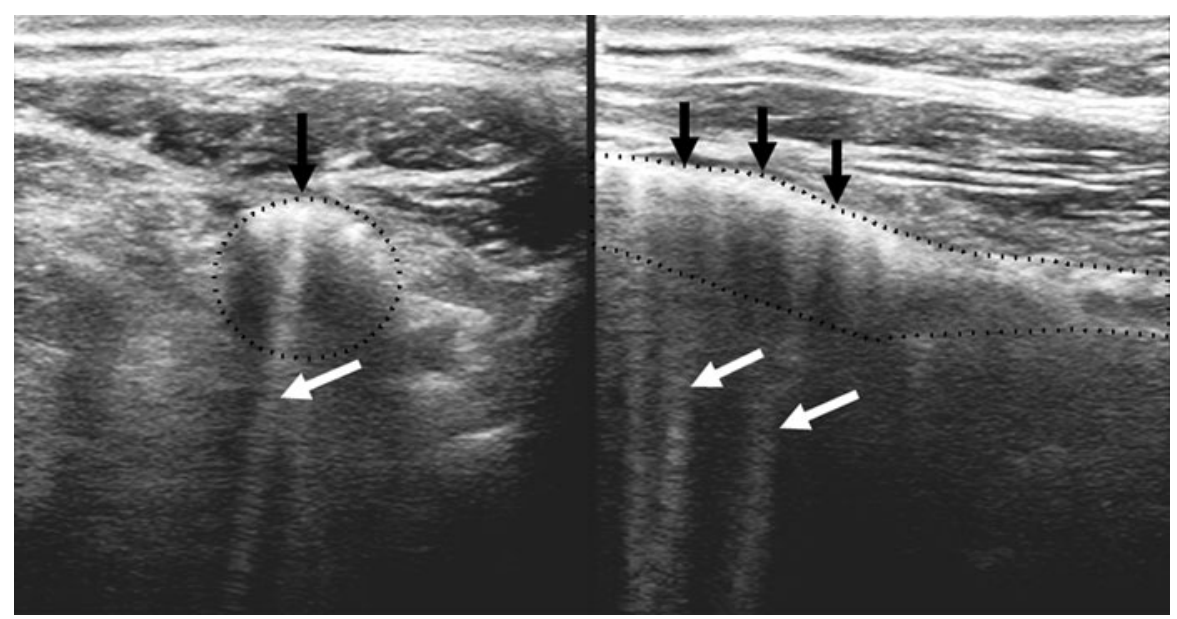


intravenous flushes. Iatrogenic gas embolism is associated with increased mortality, and is typically treated with hyperbaric oxygen [1-3].

Conflicts of interest The authors declare that they have no conflicts of interest.
Open Access This article is distributed under the terms of the Creative Commons Attribution Noncommercial License which permits any noncommercial use, distribution, and reproduction in any medium, provided the original author(s) and the source are credited.

\section{References}

1. Bessereau J, Genotelle N, Chabbaut C et al (2010) Long-term outcome of iatrogenic gas embolism. Intensive Care Med 36:1180-1187
2. Blanc $\mathrm{P}$, Boussuges $\mathrm{A}$, Henriette $\mathrm{K}$ et al (2002) Iatrogenic cerebral air embolism: importance of an early hyperbaric oxygenation. Intensive Care Med 28:559-563
3. Schlimp CJ, Loimer T, Rieger $\mathrm{M}$ et al (2006) Pathophysiological mechanism and immediate treatment of retrograde cerebral venous air embolism. Intensive Care Med 32:945 